\title{
AN RFID MODEL FOR IMPROVING WORKERS' SAFETY AT THE SEAPORT IN TRANSITIONAL ENVIRONMENT
}

\author{
Sanja Bauk ${ }^{1}$, Anke Schmeink ${ }^{2}$, Joan Colomer ${ }^{3}$ \\ ${ }^{1}$ Faculty of Maritime Studies, University of Montenegro, Montenegro \\ ${ }^{2}$ Faculty of Electrical Engineering and Information Technology, RWTH Aachen University, Germany \\ ${ }^{3}$ Barcelona School of Telecommunications Engineering, Polytechnic University of Catalonia, Spain
}

Submitted 9 September 2015; resubmitted 16 December 2015; accepted 12 February 2016; published online 24 October 2016

\begin{abstract}
The paper proposes a Radio Frequency IDentification (RFID) model for enhancing port workers' safety with reference to the Port of Bar (Montenegro) as a developing seaport operating in a transitional environment. The paper also highlights the lack of appropriate Information and Communication Technology (ICT) solutions in some developing seaports, including safety-related ones. It emphasizes the importance of safety measures through the prism of reducing the number of accidents, and gives a review of some RFID safety solutions in the harsh environments. The main part of the paper deals with the RFID worker's safety model proposed according to the Port of Bar's individual needs. The model has been presented at a logic level, while some of the physical and link layers performances between the set of an active and several passive RFID devices embedded to the port workers' Personal Protective Equipment (PPE) and the Ultra High Frequency (UHF) RFID readers located at the port perimeter, are simulated in Matlab and OMNeT++. The obtained results followed by discussions can be used as landmarks to the ports' management in adapting this or a similar model for enhancing safety measures in the port and its promoting as a safety one at the maritime market.
\end{abstract}

Keywords: seaport; workers' safety; RFID; PPE; model.

\section{Introduction}

Seaports are logistic and industrial centres of maritime nature that play an active role in the global transport system. They are characterized by spatial and functional clustering of activities that are directly and indirectly involved in seamless transportation and info-communication processes in production chains (Notteboom 2001). Harbours combine the major operations of largescale shipment, storage, and transportation. The fact that about $90 \%$ of the world trade (by volume) and $60 \%$ (by value) is performed by the sea, whereas the sea transportation is still the most cost-effective way to move row materials and goods en masse around the world (IMO 2015; UNEP, ITC, ICTSD 2012), speaks in favour of the seaports as critical nodes of the global economy.

On the other side, Information and Communication Technology (ICT) functions support contemporary multimodal, intermodal, co-modal, and/or synchromodal transportation chains and bring multiple benefits to all involved parties, inevitably including seaports, by providing real-time visibility, efficient data exchange, and better flexibility in the context of unexpected changes during a shipment (Harris et al. 2015; Moxa Inc 2008). There has been a debate about ICT being the major technological facilitator of economic globalization by creating a death of distance (Cairncross 2001) or a flat world (Friedman 2006). However, it is not possible to exclude the role of innovation in transport, most notably in containerization. It is the combination of both containerization and ICT that has allowed the reduction of shipping costs and the rise in importance of logistics and supply chain management (Jacobs 2011). Both sea ports and ICT play important roles in the world trade. Nevertheless, they are still insufficiently present among research trends of some transitional economies.

In an extensive survey of papers on ICT-related topics within transitional economies (including countries of former Eastern-Soviet Block, former Yugoslavia, and Albania) published between 1993 and 2012 (Roztocki, Weistroffer 2015) there are several papers which are explicitly concerned with ICT in the domain of transportation. These papers are the results of pro-

Corresponding author: Sanja Bauk

E-mail: bsanjaster@gmail.com

Copyright $\odot 2016$ Vilnius Gediminas Technical University (VGTU) Press http://www.tandfonline.com/TRAN 
jects' work, or they deal only with organizational, either national level. The lack of research outcomes and especially ICT applications in developing countries is a result of their unstable economies and still rigid administrations, which additionally increases digital divide and put them at risk of being further marginalized (POST 2006).

We would like to mention several papers published in the context of transitional economies, though from their titles it might not be obvious that they are considerably concerned with ICT. In addition, some of these papers have been published after 2012. For instance, the presence of contemporary ICT solutions at eight seaports of developing countries (Bar, Durrës, Constanza, Koper, Piraeus, Ploče, Rijeka, and Thessaloniki) was explored in Bauk et al. (2015). The results, unfortunately, were not encouraging. All the ports, except one (Durrës), had Electronic Data Interchange (EDI) service, while five ports, except Bar, Durrës, and Ploče, had Vessel Traffic Service (VTS) system. However, neither of the considered ports had (at the time of the survey) contemporary ICT solutions such as: Enterprise Resource Planning (ERP), Customer Relationship Management (CRM), Vessel Traffic Management Information System (VTMIS), Port Community System (PCS), nor access to Electronic Logistics Marketplace (ELM). Also, they did not use cloud computing services, neither Internet of Things (Internet of Everything) concept (Cisco 2015), etc. Furthermore, Vitić-Ćetković and Bauk (2014) concluded that the Port of Kotor (Montenegro), as an emerging cruising destination of the South Adriatic Sea, suffers the lack of transactional and added-value e-services, which are on the contrary, notably present at the official web sites of some recognized EU cruising ports (e.g., Southampton, Venice, Dover, Genoa, Civitavecchia, Helsingborg, etc.). Ivanović and Bauk (2014) offered a novel model of logistics (based on real data collected in loco over several years), developed for the coastal tourist destinations in Montenegro (Bar, Budva, Kotor, Tivat, and Herceg Novi). This model, of course, includes the ICT dimension. In addition to these research works, which are more or less concerned with seaports, sea-land transportation, passenger traffic, and corresponding ICT solutions, research works in the domain of PCS and ICT integration in the Croatian seaports (Tijan 2012; Tijan et al. 2012; Bezic et al. 2011) are also worth mentioning. It might be of interest to point out, that Tijan et al. (2012), among other points, concluded: 'Croatian seaports are currently in the phase of transition from isolated seaports to communicated seaports. It is also important to mention, that Beškovnik and Twrdy (2014) gave an original seven-pillar regional model of ports' development within a single port system of the Balkans. The uniform Information Technology (IT) platform at the port and logistics level was proposed as one of the pillars. The authors suggested a regional approach to develop standardized IT tools and platforms. They also pointed out: 'Anyhow, the main issue remains on how to motivate all transport and logistics entities to accede to this important project. Certainly, a top down model is needed, where governments and transport ministries should achieve wider agreements for the region?

\section{ICT in Improving Safety at Seaports}

Seaports can be dangerous places for port workers and pedestrians in terms of operational risks connected to (un)loading operations, port traffic management and transportation, handling manipulative equipment, warehousing, etc. Additionally, seaports usually operate 24 hours a day, in all conditions, with a variety of employees and contractors performing different activities (Roberts, Gray 2013). It is the employer's duty to preserve the health and safety of workers and to improve occupational safe systems. Unfortunately, accidents in seaports are not rare (Darbra, Casal 2004). The reason for the growing number of accidents is the increase in the seaports' turnover over the past decade. On the other side, the relatively low turnover at developing seaports should be in favour of the workers' safety, even though, as to our knowledge, there is no official statistical data concerning this issue in the aforementioned transitional countries. Regardless, improving safety measures is a must.

The world-class seaports use the latest technology based on advanced ICT solutions to help reducing the risk of accidents. These technologies include end-to-end flexible seaport surveillance solutions (Milestone 2014), i.e., sophisticated camera systems based on Closed Circuit TeleVision (CCTV) comprising a cutting-edge graphical interface and video analytics features, then radar systems connected with port transportation devices and vehicles, variety of infrared/laser, ultrasonic and/or RFID sensors for safety purposes (Hixson 2015), monitoring of cargo handling operations and allied activities (Axis 2010), different pathway anti-collision systems (Roberts, Gray 2013; SICK Pty Ltd. 2014), etc.

The simple transfer and diffusion of these and similar systems sometimes might not be fully effective for the developing countries (Avgerou 2011). In other words, setting up over-ambitious goals for employing ICT in a developing environment could end up with little hope of being effectively put into practice. Bearing this in mind, we are here looking for a feasible and cost-effective RFID system for monitoring port workers' safety at the developing Port of Bar (Montenegro).

\section{The Needs of the Port of Bar}

The Port of Bar has a favourable geographical position. With the railway line Belgrade-Bar and the road network in its hinterland, along with the intermodal transportation and traffic links with Italian ports Bari and Taranto, it could provide good connections within its rather wide gravitational area. Thanks to its advantageous geographical position, it can be developed into the distribution centre of the area. More about the Port of Bar can be found on its official web site (http://www. lukabar.me) and in the documentation of numerous regional and EU projects. In the period from 2007 to 2013, 
the port participated in the implementation of several projects concerned with:

- strengthening of intermodal transport;

- short-sea shipping possibilities;

- integrated logistics chains and attracting innovative investments;

- improving environmental impacts at ten South East European (SEE) ports (TenEcoport 2014);

- establishment of a sustainable transport system at the Adriatic coast and in the hinterland;

- enhancing environmental protection (marine/ river pollution);

- detection of dangerous materials under the sea water in the ports' area;

- development of a sustainable integral sea-land transport/traffic network;

- integration of maritime and river transport in the logistics chain;

- prevention of pollution in the SEE ports - Ecoport 8 (2013), etc.

The projects TenEcoport (2014) and Ecoport 8 (2013) are of particular importance in the context of environment protection and enhancing workers' safety. During their implementation and in the final reports, some recommendations for further actions towards improving environmental and safety management were provided. The working processes in the port were analysed in detail and the points with the highest level of risk to the workers directly employed in port operations were specified. Several in-depth interviews with the managers in the Port of Bar were performed (TenEcoport 2014), and the highlights in terms of the most common risks to which the dock workers were exposed were identified. These risks are: working outdoors in various (unfavourable) weather conditions (extremely high or low temperatures, rain, wind, etc.), exposure to dust during the transhipment of bulk cargos (grains, all types of ores and concentrates, alumina, etc.), manoeuvring with obsolete transhipment equipment and transportation devices, handling damaged cargo (bags, pallets, packages, containers, etc.), exposure to the risk of fire (especially during the summer months), etc.

In addition, port workers perform monotonous and repetitive operations, which results in fatigue increasing the risk of accidents. It is not easy to overcome all these risks, but it is feasible to upraise the safety by identifying and (periodically) locating personnel and their safety equipment.

In the next section, we are giving an overview of RFID-based solutions for enhancing working safety in harsh environments, since it could be useful in conceiving a satisfying, individually tailored solution in the case of the Port of Bar.

\section{On Some RFID Working Safety Solutions}

There is a significant number of academic survey papers in the field of RFID technology and its applications (Ngai et al. 2008; Ferrer et al. 2010). Far fewer papers deal with the implementation of RFID technology in the field of seaports' safety management, particularly in the sub-field of identifying and locating workers and their Personal Protective Equipment (PPE). Therefore, we shall firstly mention some seaports RFID safety applications in general, and then in the 3.1 sub-section, we shall give a review of three applications in the domain of PPE.

The paper on RFID model for intelligent seaports (Siror et al. 2011) is, e.g., an envisaged approach to the intelligent safety measures in the seaport made at the exemplar of Mombasa Port (Kenya). Based on the performed simulations, the model is promising and it might be used as a framework for planning future safety solutions for seaports. It is also important to mention the RFID application of the smartPORT traffic light, implemented for the first time in the Port of Hamburg (Germany) (Kathrein 2015). Seaport workers, pedestrians and vehicles are equipped with RFID chips, which communicate among themselves and with the smart traffic light via Wi-Fi network. A rather theoretical approach to similar solution, based on drafting the algorithm for establishing efficient communication between traffic density, vehicle priority, RFID controllers, and traffic lights is given in (Sigh et al. 2012). In addition, we have to mention several papers, which consider the adaptation of RFID safety solutions in the port of Cagliari (Italy). They deal with several aspects of the complex centralized control system of the seaport audio communications, video surveillance, and Web Geographical Information System (GIS) applications combined with workers' wearable RFID sensor networks (Sole 2014; Musu 2015).

In the following parts of the paper, we are focusing on the Port of Bar individual needs and challenges of working safety monitoring, concerning in the first instance identifying and examining functionality of port workers' PPE pieces equipped with RFID devices. Our aim is giving support to the Port's managers to become able to select the right RFID workers' safety system and provide the correct justification to the senior management and stakeholders to secure its buy-in (Ferrer et al. 2010). In this regard, firstly, below is given the list of some providers of RFID solutions, equipment and/or services (Table) that can be consulted by the Port of Bar managers in a case that they decide to upgrade safety measures.

It is important to mention that there are several key factors to consider when selecting an RFID solution, like: cost, reliability, security, compliancy, read/ write range, read/write speed, multi-tag capacities, environment, etc. The cost is often one of the most important, and one the most difficult to evaluate at the same time. At this initial stage of our research, it is really hard to give reliable costs evaluation. Therefore, we will be focusing on the conceptual solution and some simulation analysis.

\section{Considering Some RFID and PPE Solutions}

We proposed an RFID port workers' safety model based on the secondary literature resources and three previously developed systems for monitoring working safety in harsh environments. They identify, localize, and/or check operability of RFID devices embedded into the workers' PPE. 
Table. Supply/supporting/research RFID industry: some providers

\begin{tabular}{|c|c|c|}
\hline No & Name & Web \\
\hline 1 & Avonwood Development Ltd. & http://www.avonwood.co.uk \\
\hline 2 & ChainLink Research Inc. & http://www.chainlinkresearch.com/rfid/index.cfm \\
\hline 3 & Cisco Systems Inc. & http://www.cisco.com/c/dam/en_us/solutions/industries/docs/trans/Seaport_Overview.pdf \\
\hline 4 & DominateRFID & http://www.dominaterfid.com \\
\hline 5 & Identec Solutions & http://www.identecsolutions.com \\
\hline 6 & IdentyTag & http://www.identytag.de/rfid-produkte \\
\hline 7 & Kathrein Werke KG & http://www.kathrein.com \\
\hline 8 & Nedap N. V. & http://www.nedapidentification.com \\
\hline 9 & Phase IV Engineering Inc. & http://www.phaseivengr.com/product/pressure-temperature-rfid-uhf-wireless-sensor \\
\hline 10 & Savi Technology & http://www.savi.com \\
\hline 11 & SkyeTek Inc. & http://www.skyetek.com/solutions/rfid/personnel-tracking \\
\hline 12 & Synometrix Ltd. & http://www.synometrix.com/all-products/rfid \\
\hline 13 & Syrma Technology & http://www.syrmatech.de/index.php?content=unternehmen \\
\hline 14 & ZIH Corp. & http://www.zebra.com/us/en/solutions/location-solutions/enabling-technologies/wherenet.html \\
\hline
\end{tabular}

The first system has been commercialized and applied in the construction industry (Kelm et al. 2013), but there are no obstacles for its implementation in seaports. The second one is applied in seaports (Sole et al. 2013a, 2013b; Sole 2014). However, these two scenarios do not provide permanent real-time monitoring of the workers' PPE (safety helmets, reflective safety vests, and steel-toed safety shoes) at working place. The third one is developed at the level of prototype and it has not yet been commercialized. It is designed with the intention to provide a permanent PPE traceability, i.e., its realtime monitoring. The main shortcomings of the last mentioned system are: (a) it is not utterly unobtrusive, and (b) it is not easy to establish a proper communication between RFID tags and readers over the end points, here workers' Body Area Networks (BANs), in terms of determining the position of PPE items, what was one of the main goals of this experimental project (Barro-Torres et al. 2012). Let us consider now the three models in some more detail.

Case 1: In this case, before entering the working place, a worker has to pass through the control gate. He/ she should not pass through too quickly, since the standard UHF signal update is $1 \mathrm{~Hz}$. The worker and his/her PPE must be uniquely identifiable. The intelligent system and user interface provides real-time feedback to the worker. The system is able to recognize multiple tags simultaneously, thus the worker is immediately notified if the ID is not proper and/or which PPE component(s) is(are) missing. Once the worker has been properly identified and proved to be wearing the required equipment, the turnstile at the terminal entrance opens, otherwise entry will be denied. The scheme of this scenario is given in Fig. 1. The main shortcoming of this solution is the impossibility of locating and monitoring workers and their PPE pieces after passing through the gate, unless the whole working area is covered by the sufficient number of the long-range RFID readers.

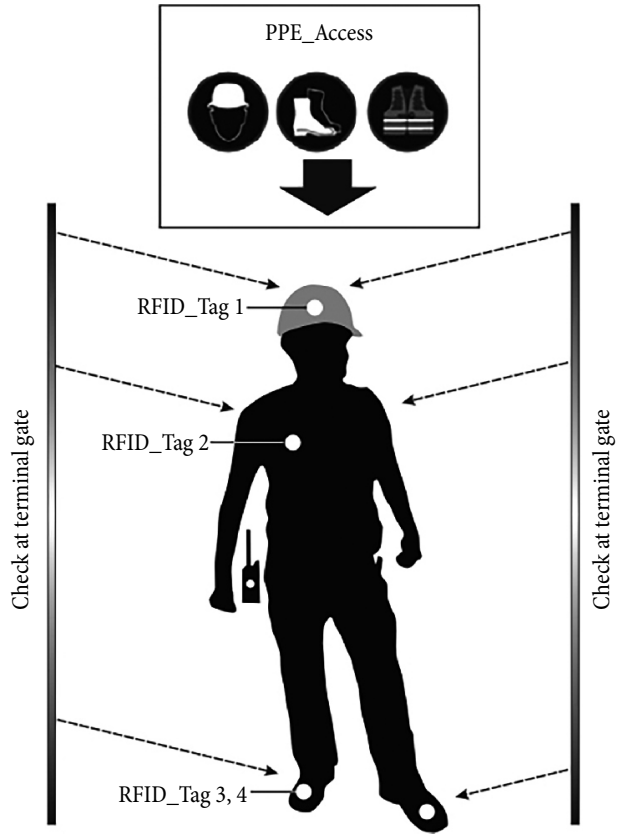

Fig. 1. Inspection of worker's PPE at entrance gate - adapted from Kelm et al. (2013)

Case 2: In this case, assuming that the worker has passed the identification and PPE control at the entrance gate, the CCTV system installed at the terminal provides continuous monitoring with the intention to discover if the worker properly wears the PPE at the working place. In the case of non-use, or improper use of PPE, the technician responsible for the video surveillance will warn the worker by sound or text message alarm via the port wireless network (Wi-Fi) and PDA (Personal Digital Assistant) device attached to the worker's belt (Sole 2014). Wearable sensor network in this case consists of passive RFID and Wireless Identification and Sensing Platform (WISP) devices, which 


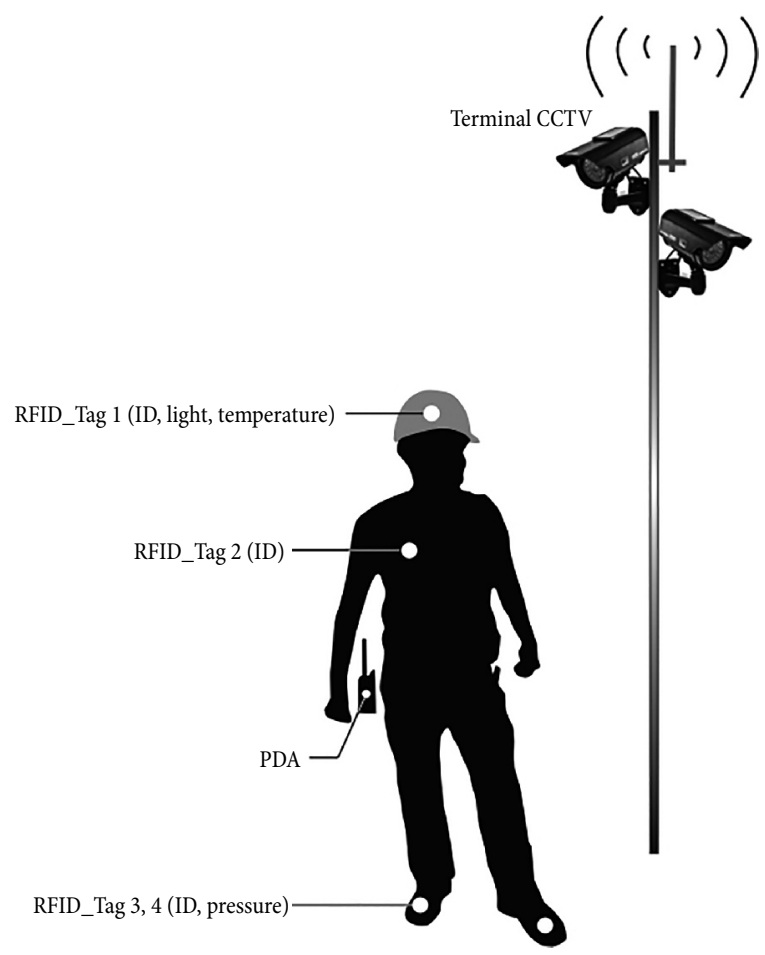

Fig. 2. Checking the proper usage of the worker's PPE at the terminal by means of CCTV - adapted from Sole et al. (2013a)

provide the ID and ambient light and temperature (helmet), and worker's plantar pressure (shoes) data. Fig. 2 gives a scheme of this scenario. It is presented as an example of a possible port workplace safety solution, but it has not been recommended for application in the case of the Port of Bar. The centralized monitoring system of the CCTV connecting with the port Web GIS maps, RFID/WISP sensors and readers, might be too complicated for implementation at the present stage of the Port of Bar development. This model has been recently re-engineered towards the Internet of Things concept (Musu et al. 2014; Musu 2015). In this regard, among other things, it excludes workers' PDA devices and provides direct communication between worker's clothing with embedded RFID tags and readers placed at the strategic port's locations. A smart software system is used for locating workers, their PPE functionality, and helmet position, thanks to the accelerometer installed in it. The segment of this safety solution that provides direct (periodical) communication between tags and readers through the intelligent software back-end system might be partially implemented in the Port of Bar, in the manner presented in the next section.

Case 3: This system can be treated as a novel one in comparison to the previous two systems. It is composed of Body Area Network (BAN) that collects information from the RFID tags by the readers located throughout the workers' clothing. The Central Unit Microcontroller (CUM) processes the data and transmits them by radio module to the external mesh network composed of the set of end nodes (workers' BANs), routers, and the coordinator. The coordinator collects and stores the data

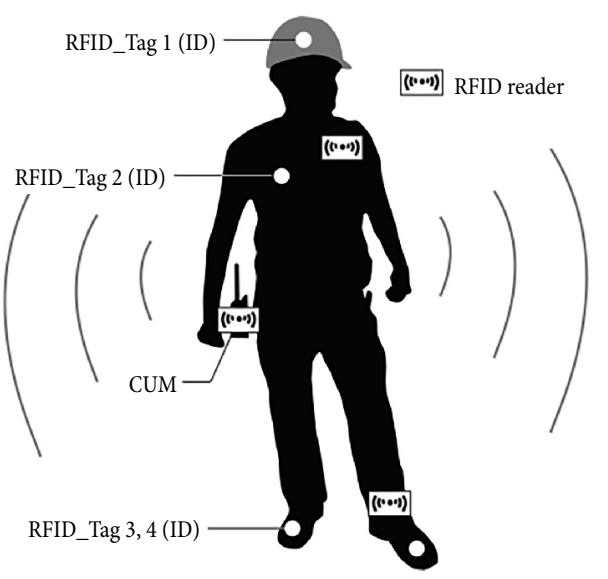

Fig. 3. Self-checking system of the worker's PPE proper usage - adapted from Barro-Torres et al. (2012)

coming from the end nodes, configures nodes and performs synchronization. End nodes are the critical part of the system. They are composed of central unit microcontroller, radio module and RFID readers. The readers are located at strategic points in the clothing, since the technology used allows them to be read at close range. The detection rate clearly increases when the antennas of the reader and the tag are in parallel, while it decreases dramatically when the antennas are oriented orthogonally. To avoid the null spots, different alternatives have to be weighted up in order to modify the antenna radiation pattern. The scheme of this scenario is given in Fig. 3. We do not recommend this model to be implemented at the Port of Bar, since it is complex, intrusive, and the central microcontroller is currently at the level of a prototype.

By merging Case 1 and Case 2 scenarios and some modifications, an acceptable model for the Port of Bar can be conceived. Instead of scanning and alerting workers at the port gate, we proposed collecting data from an active and several passive RFID tags attached to/embedded into the workers PPE pieces by UHF RFID readers (Musu 2015) located at strategic points within the port perimeter. These readers can be connected by Wi-Fi or Ethernet to the port backend info-communication system through which the status of the tags and the information returned can be read and stored in the database.

\section{Proposed Model and Some Simulation Analysis}

Although the range of negative working and environmental impacts in the Port of Bar is quite large, prospective application of PPE equipped with RFID tags will strengthen port workers' safety and increase the level of their corporate safety culture. Previously described systems Case 1 and Case 2 can be adapted by the Port of Bar with some conceptual and technological modifications. Namely, an active UHF RFID-enabled worker's badge can transmit the ID number at present intervals to the port's fixed readers. These ID badge can be worn around the neck, attached to clothing or placed in the pocket and it can be read up to $500 \mathrm{~m}$ (Swedberg 2010). 
It allows the smart software system and RFID hardware to track the number-identities of the port worker at any time, as well as, in some cases, pinpointing the worker's location. The system memorizes the 'last seen location data' for each worker. On the other side, each time the worker is in the range of the reader(s), approximately in the range of $10 \mathrm{~m}$, the control system will have the information on the status of passive RFID tags attached to the PPE, i.e., if they: work correctly, don't work correctly, or don't work at all. Fig. 4 shows an example of the worker who does not have a helmet on site, and whose shoe is damaged. In such a situation, the worker must be alerted to go to the central for wearing/changing PPE.

Hence, a worker's PPE is composed of a helmet, safety vest and shoes with passive UHF RFID tags attached/embedded. These tags must unambiguously identify a particular safety garment and communicate via reader(s) to the port's safety control centre which provides alarm to the worker's Handheld Radio Device (HRD) in a case a certain tag(s) does(do) not work (at all/properly). It is important to mention that the RFID inlay provides data on radio frequency functionality of any tag (Armstrong 2013). The tagged PPE should be designed, produced, and tested in accordance with the port's needs by specialized companies such as: Extronics, Identytag, Omni-ID, ScanLink, Syrmatech, etc.

All readers are connected via Wi-Fi or through the port's Ethernet through which the status and the information returned can be read and stored in the beckend server connected to the central control system. If a worker is not wearing the mandatory and functional PPE clothes, or if he/she is in an extremely dangerous zone, a signal alarm alerts of a dangerous situation.

The system should be used as an emergency preparedness one, as well (Vermesan et al. 2010). In the event of an emergency, the workers should be alarmed to leave the zone of potential danger and come immediately to the appointed place. At the appointed place, the workers' current position can be determined and all PPE tags identified and checked.

In the following sub-sections we shall analyse the channel between workers' wearable sensor sub-network composed of an active UHF RFID ID badge and four passive UHF RFID tags (attached to the helmet, vest, and shoes), and the UHF readers located at the port perimeter. The readers should work at EU standardized carrier frequency range of $865-869 \mathrm{MHz}$ and offer a flexible platform to evaluate the identification and status of the RFID transponders by supporting EPC (Class 1) Gen2 standard.

The layout of the Port of Bar container terminal is used as a base for some simulation analysis of the proposed workers' wireless safety model (Fig. 5).

Since our goal is not to offer the final solution, but to provide an insight to the managers in the Port of Bar into the existing solutions of the kind and a framework for an individually-tailored solution, we considered it important to analyse some of the key parameters of wireless networks. Regardless of the model which will be adapted, wireless networks will be in any case essential segments of the whole project: whether it is a BAN that connects PPE RFID active and passive devices, or

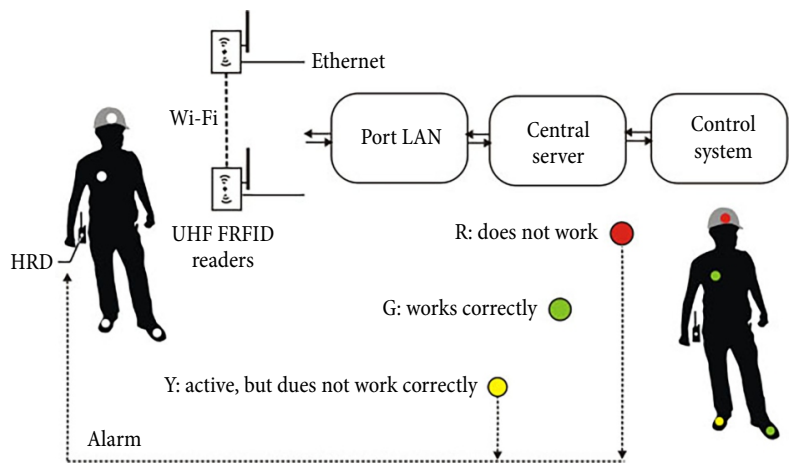

Fig. 4. An RFID model for port workers' safety monitoring - adapted from Musu (2015)

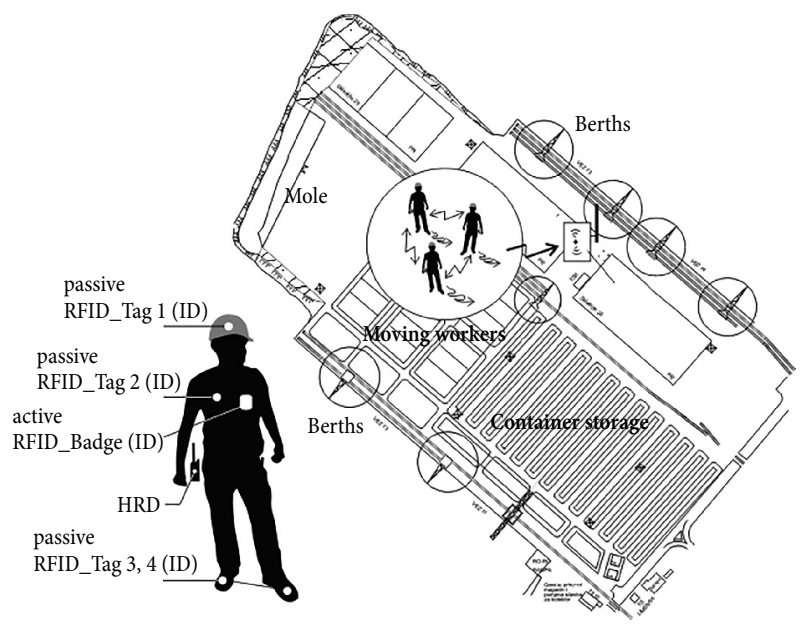

Fig. 5. An RFID occupational safety model on the layout of the Port of Bar container terminal

Wireless Local Area Network (WLAN) that connects UHF RFID readers with PCs, routers and other components of the port network infrastructure. Therefore, in the first set of simulations, we gave some analysis of the channel between the transmitter and receiver at the physical and the link layers. This might be helpful for the managers in understanding the principles of wireless networks and later on making the decision on adapting certain workplace safety systems. The simulation experiments have been done in Matlab. In the second set of simulation experiments, the channel between the moving nodes (the sub-networks of port workers' RFID devices) and several fixed nodes (RFID readers) located over the Port of Bar container terminal operational area, was analysed. These simulation experiments were realized in an OMNeT++ environment. The obtained results are discussed in the following sub-sections.

\subsection{Simulation Model 1:}

\section{Wireless Networks' Performances}

The first set of simulation experiments was performed in Matlab (ver. 7.12.1), by an Intel(R) Core ${ }^{\mathrm{TM}}$ i5 processor on $2.4 \mathrm{GHz}$ (4GB RAM). The key steps within these Matlab simulations are as follows:

- Definition of the simulation parameters: carrier frequency, distance between transmitter and receiver, a sequence of input bits, number of iterations, and Signal-to-Noise-Ratio (SNR) range; 
- Calculation of Free Space Path Loss (FSPL):

$F S P L=\left(\frac{4 \cdot \pi \cdot d \cdot f}{c}\right)^{2}$,

where: $d$ is the distance between the transmitter and the receiver $[\mathrm{m}] ; f$ is the frequency of the carrier $[\mathrm{Hz}] ; c$ is the speed of light in vacuum;

- Application of the Binary Phase-Shift Keying (BPSK) and Quadratic Phase-Shift Keying (QPSK) modulation schemes on real and complex signal components respectively;

- Generation of the Gaussian noise and computation of the standard deviation for each SNR value:

$P_{\text {noise }}=\sqrt{\frac{P_{\text {signal }}}{S N R \cdot F S P L}}$,

where: $P_{\text {noise }}$ is the power of noise [W]; $P_{\text {signal }}$ is the power of transmitting signal [W]; SNR is the signal-noise-ratio;

- Simulation of Additive White Gaussian Noise (AWGN);

- Generation of the recovering (source) signal by the Wiener filter which minimizes the mean square error between the estimated random process and the desired one;

- Computation of the number of Bit Error Rate (BER) after the slicer, i.e., part of the code that compares the original signal with the recovered one, point by point, specifying if it is well recovered or not;
- Plotting graphics: BER vs. SNR (Figs 6 and 7).

Based on the source code in Matlab, the relation between the transmitted signal BER and SNR have been analysed. In the first case, the considered relation has been examined for characteristic carrier frequencies in different wireless technologies (Mahalik 2007): $915 \mathrm{MHz}$ (ZigBee), $2.4 \mathrm{GHz}$ (Bluetooth), and 3.1 GHz (Ultra Wide Band). In addition to the simulation experiments for these typical WLAN carriers' frequencies, the simulations for White-Fi have been performed, as well. Two characteristic frequencies in the White-Fi domain have been analysed: $470 \mathrm{MHz}$ and $710 \mathrm{MHz}$. By using the White-Fi signal, the absorption can be easily avoided and otherwise unused TV frequencies might be exploited. In order to achieve this, the new technologies and rules are currently developing (Poole 2015), such as cognitive radio, geographic sensing, etc. It is clear that in all cases the BER decreases with the increase of SNR (Fig. 6). In addition, it is clear that the higher frequency causes higher BER and inversely. The simulations have been made for the distance between the transmitter and receiver of $10 \mathrm{~m}$, and they have been performed through several thousand runs in order to achieve smoother curves.

Similar simulations have been done for different distances between the transmitter and receiver (Fig. 7), i.e., for 10, 20, and $30 \mathrm{~m}$. The BER decreases with rising SNR in all the considered cases, in a manner that a greater distance corresponds to a higher BER and conversely. The simulations have been run like in the

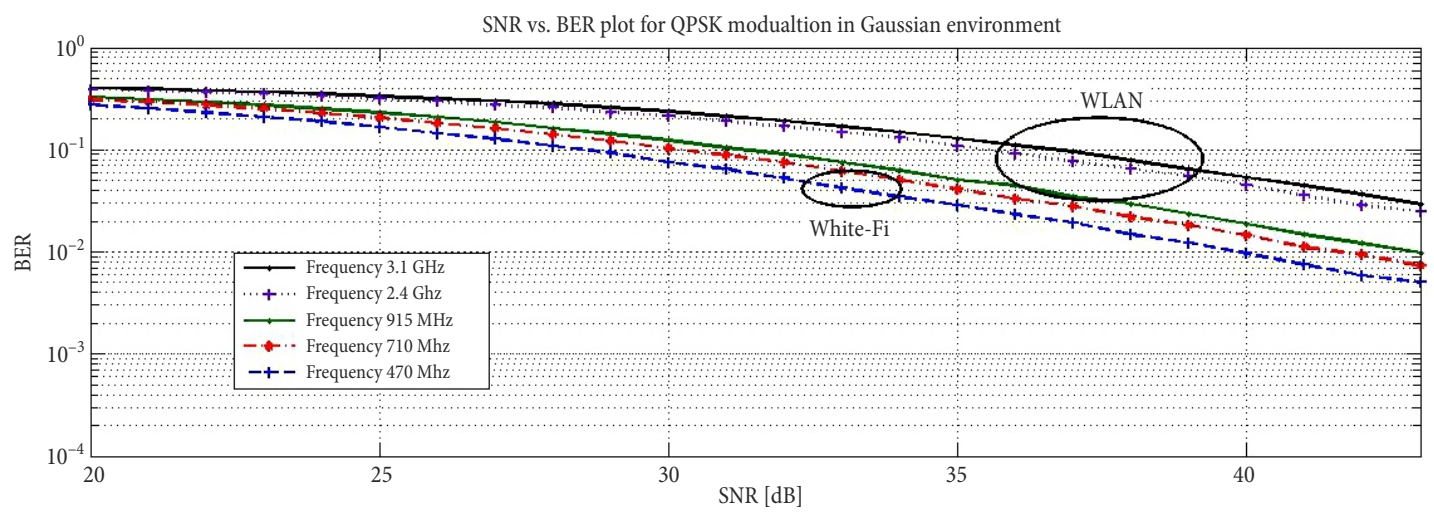

Fig. 6. BER vs. SNR for three characteristic WLANs and two White-Fi carriers' frequencies

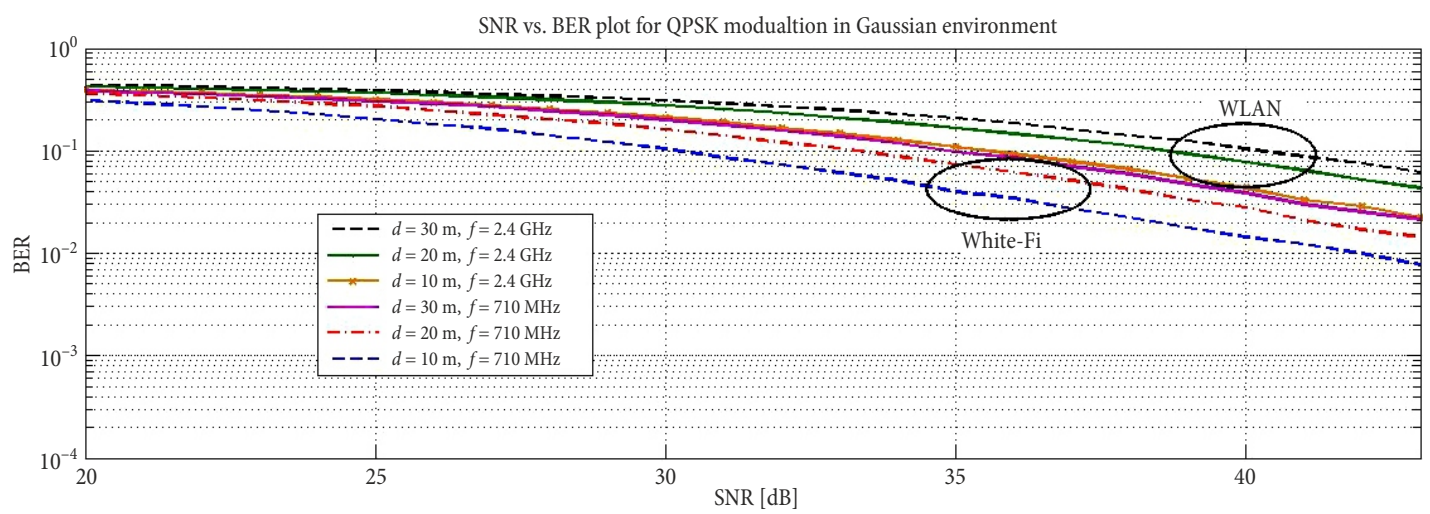

Fig. 7. BER vs. SNR for three different distances at two characteristic WLAN and White-Fi carriers' frequencies 
previous cases trough several thousand trials. They have been realized by using the BPSK modulation scheme, and it is clear that the BER decreases to E-02 as SNR reaches ca. $45 \mathrm{~dB}$.

The obtained simulation results in the considered cases (Figs 6 and 7) speak in favour of the applied modulation schemes, path loss and noise models. The tradeoff between BPSK and QPSK modulation schemes has been simulated, too, and it shows that the BER is slightly lower in the case of BPSK, but it is negligible in terms of the transmitted data amount, which is doubled by using QPSK.

\subsection{Simulation Model 2:}

\section{Moving-Fix Nodes Channel Analysis}

The second set of simulation experiments has been performed in $\mathrm{OMNeT++}$ (ver. 4.6) environment, by an Intel(R) $\operatorname{Core}^{\mathrm{TM}}$ i5 processor on $2.4 \mathrm{GHz}$ (4GB RAM). The average time per simulation was approximately $15 \mathrm{~min}$. OMNeT++ is a relatively new simulation tool. It is a modular, extensible, component-based $\mathrm{C}++$ simulation library and framework. The main use of this tool is to simulate, model, and build all kinds of networks: wired and wireless, on-chip, queuing ones, etc. This tool provides component architecture for models. Components are programmed in $\mathrm{C}++$ and then assembled into larger schemes using a high-level network description language (OpenSim Ltd. 2015).

The $2 \mathrm{D}$ simulation area is limited within $1000 \mathrm{~m}$ in both directions. It includes four randomly moving port workers' sub-networks and four-fixed port's nodes (readers). The change interval is $1 \mathrm{sec}$ with $0.1 \mathrm{sec}$ of standard deviation. This means that over $1 \mathrm{sec}$ each node will make a move at a specified speed. The speed was settled to emulate the movement of a human person, i.e., $3 \mathrm{~m} / \mathrm{sec}$. The type of selected channel was the Rician fading channel. The transmission power was set to $1 \mathrm{~mW}$ or $-30 \mathrm{~dB}$. Fig. 8 shows the relation of the reception power of the fixed nodes and the delay. The distance and delay are linked by the speed of transmission of the signal. It is easy to notice that the received power is less as the distance (or the delay) decreases.

If we introduce the obstacles, the scatter function will be changed (Fig. 9). As the simulation experiment

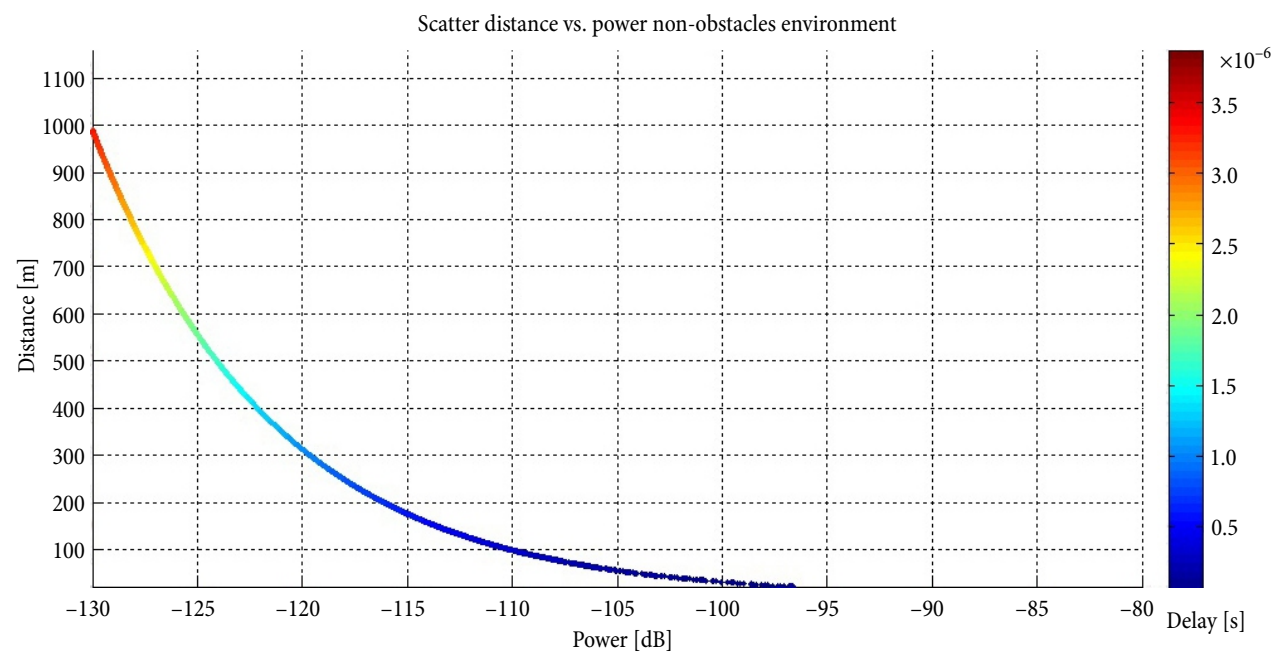

Fig. 8. Scatter function of the distance vs. received power for a non-obstacle scenario

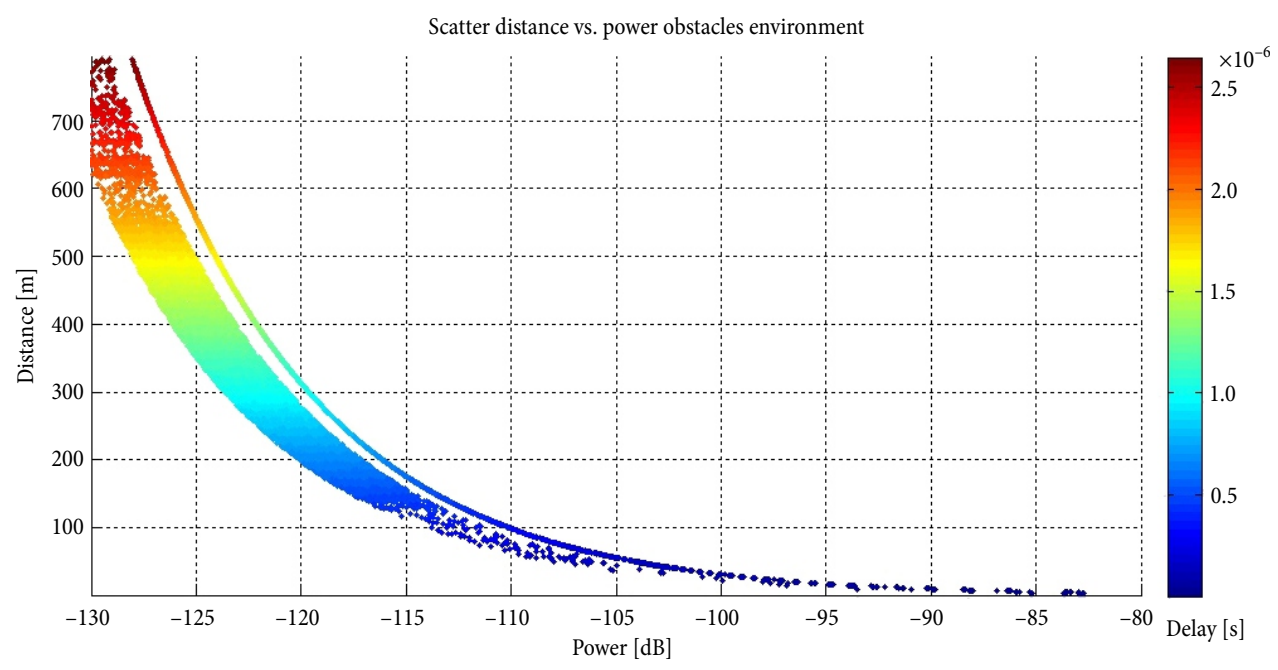

Fig. 9. Scatter function of the distance vs. received power for a scenario with obstacle 
has been done over the layout of the Port of Bar container terminal, the obstacles were imaginary containers blocks (12 of them). The obstacles' approximate measures were $200 \times 100 \times 4 \mathrm{~m}$. They were metallic with a specific relative permittivity and permeability, which also affects the channel. When the distance/delay was big, the received power was very low and vice versa. The scatter diagram in the scenario with obstacles has two significant shapes. The thin one represents the line of the sight signal, while the thicker one represents the reflection or the signals that pass through the obstacle. The difference between the received power of the line of a sight signal and the received power of a reflected or a signal that pass through an obstacle is approximately 1-5 dB. This is completely meaningful as long as the signal through an obstacle or a reflected signal is received with less power.

Over the simulation scenario with the obstacles, different modulation types: BPSK, QPSK, 16QAM, 64QAM, were used. It is easy to notice that BER decreases if SNR increases in for each modulation scheme (Fig. 10). The curves are not smooth, resulting from the random nature of the simulation environment, and the presence of the obstacles. Depending on the modulation type, BER is different. Namely, BPSK modulation works with only one bit per symbol, and it is therefore the simplest one. On the other hand, if the simulation used QPSK, the number of bits per symbol was two, if it used 16QAM, the number of bits per symbol was four, and finally, for 64QAM modulation type, the number of bits per symbol was six. This causes the proportional trade-off between BER and the number of bits transmitted.

The simulations outcomes can be summarized as follows:

- both scatter functions (for the scenario without and with obstacles) contain the lines of sight signal components and their values are the same;

- the attenuation of the signal caused by the block of containers' obstacle cannot be neglected (it's approximately $1-5 \mathrm{~dB}$ );

- the scenario with obstacles needs a higher value of SNR in order to achieve the same level of BER as in the case of non-obstacle environment.

\section{Conclusions}

The paper describes the current situation in the developing seaports regarding the implementation of innovative ICT solutions, with emphasize on the Port of Bar (Montenegro). It has been observed that some seaports in transitional economies do not have contemporary info-communication business and safety solutions. Our intention was to identify where the implementation of new ICT tools is necessary, but also feasible. Consequently, we came up with the idea that enhancing port workers' safety by introducing RFID technology might be useful and cost-effective solution in the initial phase of adapting modern ICT safety models.

Throughout the simulation experiments in Mat$l a b$ and $O M N e T++$, the performances of the channel between the transmitters and receivers placed at appropriate locations within the seaport perimeter have been tested over the Port of Bar's layout. The simulations in Matlab have been performed for the simplified oneto-one (transmitter-receiver) communication channel, while the simulations in $O M N e T++$ have been realized for the case of several constantly moving workers' wearable sub-networks and several fixed port's nodes. The obtained results are presented in the 4.1 and 4.2 subsections, while the following can be summarized:

- For different carrier frequencies and distances between the transmitter and receiver, a satisfying level of BER is achieved by using Binary PhaseShift Keying (BPSK) and Quadratic Phase-Shift Keying (QPSK) modulation schemes above real and complex signal components, respectively, while Wiener filter was successfully used for recovering source signal in the Gaussian environment;

- In addition to standard frequencies for wireless communications $(915 \mathrm{MHz}, 2.4 \mathrm{GHz}$, and $3.1 \mathrm{GHz}$ ) between the transceivers, two characteristic frequencies from White-Fi spectra $(470 \mathrm{MHz}$, and $710 \mathrm{MHz}$ ) have been examined, while the satisfying level of BER has been achieved, as well;

- In the seaport environment without and with the obstacles (container blocks) in OMNeT++ environment: the scatter functions of the distances vs. received powers have been generated, and SNR

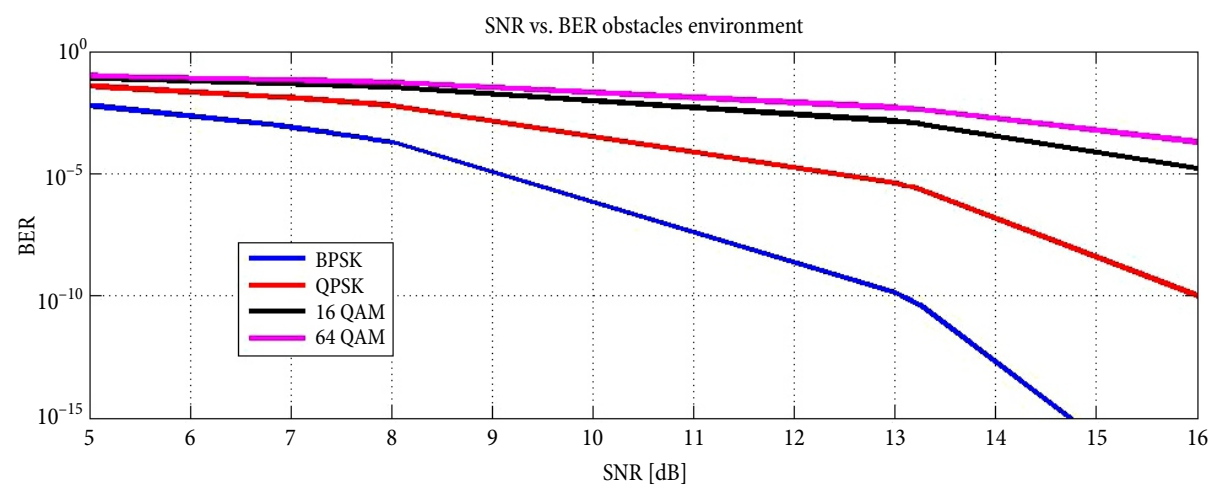

Fig. 10. Scenario with obstacles: SNR vs. BER for BPSK, QPSK, 16QAM, 64QAM 
vs. BER for BPSK, QPSK, 16QAM, and 64QAM modulations schemes compared;

- It has been concluded that both scatter functions, in the simulation environment with and without obstacles, contain the line of sight signals, and that their values are the same in both cases;

- In the scenario in OMNeT++ that includes the obstacle, the attenuation of the signal of $1-5 \mathrm{~dB}$ was noticed; and,

- By comparing plots for SNR vs. BER in the cases of different modulation schemes: BPSK, QPSK, 16QAM, and 64QAM, it is clear that the scenario with obstacles needs a higher SNR value in order to achieve the same BER value characteristic for the same environment without the obstacles.

The presented findings might be of importance to the managers in the considered developing seaport, since they can be used as landmarks in negotiations with senior managers and stakeholders in the port in order to provide funds, as well as in negotiations with ICT companies being in charge of implementing the proposed workers' safety model.

Active RFID workers' badges and passive RFID tags for identification and periodical locating, together with the PPE pieces (helmets, vests, and shoes) should have both direct and indirect positive effects. The PPE protects the workers from injuries, and this is direct positive effect of the proposed safety solution. Indirectly, by regular usage of the PPE garments equipped with RFID devices, including alarm capabilities, raises the port workers' and supervisors' awareness of the occupational risks, as well as the level of the corporate culture.

However, the proposed model for enhancing port workers' safety has certain shortcomings. They are primarily related to the RFID technology and backend network infrastructure limitations. The proposed technology has several significant beneficial aspects, such as: batch readability, resistance to some harsh environment conditions, large information storage and processing capability, etc. On the other hand, it has also several substantial disadvantages (Kapoor et al. 2009), such as: reading error, privacy/security concerns, computing bottleneck, cost-benefit issues (vagueness of investments returns and difficulties in estimating opportunity costs), risk of obsolescence, inter-operability (global) standards issues, etc. In addition to these rather general shortcomings of the RFID technology, there is one more, specifically related to the issue in matter, i.e., inability of monitoring workers in real time and checking whether the workers wear their PPE correctly. BarroTorres et al. (2012) have done the efforts for resolving this problem, but the proposed solution has some limitations and it has not yet been commercialized. Therefore, the real-time locating and tracking of port workers and their PPE garments by employing Internet of Things concept, might be considered as next step in developing this model, although it is more expensive.

There is an additional problem which is not technical in its nature, but it should not be ignored, either. Namely, there are several organizational and ethical issues, which deserve to be examined in this context. The level of the seaport's both senior managers' and stake- holders' readiness for providing funds and employing the proposed occupational safety solution should be assessed. Also, the willingness of the workers to become the active constituents of the proposed network is to be assessed. The achieved results of planned soft examinations might cause some modifications in the proposed RFID port workers' safety scenario.

\section{References}

Armstrong, S. 2013. 3 Things to Know About UHF RFID Tags. Available from Internet: http://blog.atlasrfidstore.com/ basics-of-uhf-passive-rfid-tags

Avgerou, C. 2011. Discourses on innovation and development in information systems in developing countries research, in R. D. Galliers, W. L. Currie (Eds.). The Oxford Handbook of Management Information Systems: Critical Perspectives and New Directions, Chapter 25: 647-671.

http://doi.org/10.1093/oxfordhb/9780199580583.003.0029

Axis. 2010. Vizag Seaport Goes High Tech with Axis Network Surveillance. 2 p. Axis Communications AB, Sweden. Available from Internet: http://www.axis.com/files/success_stories/ss_trn_vizag_seaport_40126_en_1007_lo.pdf

Barro-Torres, S.; Fernández-Caramés, T. M.; Pérez-Iglesias, H. J.; Escudero, C. J. 2012. Real-time personal protective equipment monitoring system, Computer Communications 36(1): 42-50. http://doi.org/10.1016/j.comcom.2012.01.005

Bauk, S.; Šekularac-Ivošević, S.; Jolić, N. 2015. Seaport positioning supported by the combination of some quantitative and qualitative approaches, Transport 30(4): 385-396. http://doi.org/10.3846/16484142.2013.815657

Beškovnik, B.; Twrdy, E. 2015. Developing regional approach for transport industry: the role of port system in the Balkans, Transport 30(4): 437-447. http://doi.org/10.3846/16484142.2014.938696

Bezic, H.; Tijan, E.; Aksentijevic, S. 2011. Port community systems - economic feasibility evaluation, Ekonomski vjesnik Econviews: Review of Contemporary Business, Entrepreneurship and Economic Issues 24(2): 247-256.

Cairncross, F. 2001. The Death of Distance: How the Communications Revolution is Changing our Lives. Harvard Business Press Books. 336 p.

Cisco. 2015. Cisco Smart+Connected Communities. Cisco Systems, Inc. 5 p. Available from Internet: http://www.cisco. $\mathrm{com} / \mathrm{c} / \mathrm{en} / \mathrm{us} /$ products/collateral/se/internet-of-everything/ brochure-c02-736084.pdf

Darbra, R.-M.; Casal, J. 2004. Historical analysis of accidents in seaports, Safety Science 42(2): 85-98. http://doi.org/10.1016/S0925-7535(03)00002-X

Ecoport 8. 2013. ECOPORT 8 Project: Environmental Management of Transborder Corridor Ports. Code SEE/A/218/2.2/X. Available from Internet: http://www.ecoport8.eu

Ferrer, G.; Dew, N.; Apte, U. 2010. When is RFID right for your service?, International Journal of Production Economics 124(2): 414-425. http://doi.org/10.1016/j.ijpe.2009.12.004

Friedman, T. L. 2006. The World Is Flat: The Globalized World in the Twenty-first Century. Penguin Books. 593 p.

Harris, I.; Wang, Y.; Wang, H. 2015. ICT in multimodal transport and technological trends: unleashing potential for the future, International Journal of Production Economics 159: 88-103. http://doi.org/10.1016/j.ijpe.2014.09.005

Hixson, R. 2015. Radio frequencies keep Edmonton workers safe, Journal of Commerce, 16 July 2015. Available from Internet: http://journalofcommerce.com/OHS/News/2015/7/Radiofrequencies-keep-Edmonton-workers-safe-1008947W 
IMO. 2015. IMO Profile: Overview. International Maritime Organization (IMO). Available from Internet: http://business. un.org/en/entities/13

Ivanović, Ž.; Bauk, S. 2014. Multiphase approach to developing model of logistics for coastal tourist destinations, Promet Traffic\&Transportation 26(5): 405-418. http://doi.org/10.7307/ptt.v26i5.1458

Jacobs, W. 2011. The Role of Port Infrastructure and Logistics in Global Networks. Netherlands. 5 p. Available from Internet: http://www.iss.nl/fileadmin/ASSETS/iss/Documents/ DevISSues/Jacobs_WEB.pdf

Kapoor, G.; Zhou, W.; Piramuthu, S. 2009. Challenges associated with RFID tag implementations in supply chains, European Journal of Information Systems 18(6): 526-533. http://doi.org/10.1057/ejis.2009.41

Kathrein. 2015. RFID Technology from Kathrein Makes Traffic Light Smart. Kathrein-Werke KG. Available from Internet: http://www.kathrein.com/en/newsroom/news/announcement/news/rfid-technology-from-kathrein-makes-trafficlight-smart

Kelm, A.; Laußat, L.; Meins-Becker, A.; Platz, D.; Khazaee, M. J.; Costin, A. M.; Helmus, M.; Teizer, J. 2013. Mobile passive radio frequency identification (RFID) portal for automated and rapid control of personal protective equipment (PPE) on construction sites, Automation in Construction 36: 38-52. http://doi.org/10.1016/j.autcon.2013.08.009

Mahalik, N. P. (Ed.). 2007. Sensor Networks and Configuration: Fundamentals, Standards, Platforms, and Applications. Springer Berlin Heidelberg. 509 p. http://doi.org/10.1007/3-540-37366-7

Milestone. 2014. Seaport Surveillance Solutions: End-to-End Systems for Any Seaport Large or Small. 2 p. Milestone Systems A/S. Available from Internet: http://www.milestonesys.com/files/Verticals/Seaports/Seaports_vertical_ flyer_ENG_web.pdf

Moxa Inc. 2008. Video Surveillance System for Seaport. Available from Internet: http://moxa.bossinfo.com.tw/newsletter/connection/2008/02/Video_surveillance_system.htm

Musu, C. 2015. Wearable Sensors Networks for Safety Applications in Industrial Scenarios: Doctoral Dissertation. University of Cagliari, Italy. 111 p. Available from Internet: http:// veprints.unica.it/1115

Musu, C.; Popescu, V.; Giusto, D. 2014. Workplace safety monitoring using RFID sensors, in 2014 22nd Telecommunications Forum (TELFOR), 25-27 November 2014, Belgrade, Serbia, 656-659.

http://doi.org/10.1109/TELFOR.2014.7034494

Ngai, E. W. T.; Moon, K. K. L.; Riggins, F. J.; Yi, C. Y. 2008. RFID research: an academic literature review (1995-2005) and future research directions, International Journal of Production Economics 112(2): 510-520. http://doi.org/10.1016/j.ijpe.2007.05.004

Notteboom, T. E. 2001. Spatial and functional integration of container port systems and hinterland networks in Europe, Land Access to Sea Ports 113: 5-55.

OpenSim Ltd. 2015. OMNeT++: Discrete Event Simulator. Available from Internet: https://omnetpp.org

Poole, I. 2015. IEEE 802.11af White-Fi Technology - an Overview of the IEEE 802.11af or White-Fi Proposal for Wi-Fi Using the TV White Spaces Using Cognitive Radio Technology. Available from Internet: http://www.radio-electronics.com/ info/wireless/wi-fi/ieee-802-11af-white-fi-tv-space.php

POST. 2006. ICT in Developing Countries, Postnote No 261. Parliamentary Office of Science and Technology (POST), UK Parliament. 4 p. Available from Internet: http://www. parliament.uk/documents/post/postpn261.pdf
Roberts, B.; Gray, M. 2013. Improving pedestrian safety in container ports and terminals, Port Technology 59: 40-42.

Roztocki, N.; Weistroffer, H. R. 2015. Information and communication technology in transition economies: an assessment of research trends, Information Technology for Development 21(3): 330-364.

http://doi.org/10.1080/02681102.2014.891498

SICK Pty Ltd. 2014. Anti-Collision Systems Ensure Safe Container-Terminal Operations. Available from Internet: http:// www.safetysolutions.net.au/content/materials-handling/ article/anti-collision-systems-ensure-safe-container-terminal-operations-703787960

Sigh, H.; Kumar, K.; Kaur, H. 2012. Intelligent traffic lights based on RFID, International Journal of Computing and Business Research 2012: 1-10. Available from Internet: http://www.researchmanuscripts.com/isociety2012/13.pdf

Siror, J. K.; Huanye, S.; Dong, W. 2011. RFID based model for an intelligent port, Computers in Industry 62(8-9): 795810. http://doi.org/10.1016/j.compind.2011.08.004

Sole, M. 2014. Communication Technologies and Data Processing for Safety: Doctoral Dissertation. University of Cagliari, Italy. 110 p. Available from Internet: http://veprints.unica.it/927

Sole, M.; Musu, C.; Boi, F.; Giusto, D.; Popescu, V. 2013a. Control system for workplace safety in a cargo terminal, in IWCMC 2013: the 9th International Wireless Communications \& Mobile Computing Conference, 1-5 July 2013, Cagliari, Sardinia, Italy, 1035-1039.

http://doi.org/10.1109/IWCMC.2013.6583699

Sole, M.; Musu, C.; Boi, F.; Giusto, D.; Popescu, V. 2013b. RFID sensor network for workplace safety management, in 2013 IEEE 18th Conference on Emerging Technologies \& Factory Automation (ETFA), 10-13 September 2013, Cagliari, Italy, 1-4. http://doi.org/10.1109/ETFA.2013.6648157

Swedberg, C. 2010. Active UHF RFID tags muster support for oil rigs, RFID Journal 2010: 1-2. Available from Internet: http://www.rfidjournal.com/articles/pdf?8000

TenEcoport. 2014. Feasibility Study for the Port of Bar. WP 5 Act 5.2. Feasibility Studies for Port Operators. TEN ECOPORT project - Code SEE/D/0189/2.2/X. Project 'Transnational ENhancement of ECOPORT8 Network'. Institute of Marine Biology (BIOKOTOR), University of Montenegro, 48 p. Available from Internet: http://www.tenecoport.eu/ images/FeasibilityStudy1_Port_of_BAR.pdf

Tijan, E. 2012. ICT enablement of administrative processes in Croatian seaports, Proceedings of the Graduate Student Consortium - 25th Bled e-Conference 2012, 17-21 June 2012, Bled, Slovenia, 55-60.

Tijan, E.; Agatić, A.; Hlača, B. 2012. The necessity of port community system implementation in the Croatian seaports, Promet - Traffic\&Transportation 24(4): 305-315. http://doi.org/10.7307/ptt.v24i4.444

UNEP; ITC; ICTSD. 2012. Trade and Environment Briefings: International Transport. United Nations Environment Programme (UNEP), International Trade Centre (ITC), International Centre for Trade and Sustainable Development (ICTSD). 6 p. Available from Internet: http://www.intracen. org/uploadedFiles/Policy\%20Brief\%205\%20internationaltransport.pdf

Vermesan, O.; Gregersen, M.; Andersen, E., et al. 2010. Recommended Guidelines for Deployment of Radio Frequency Identification (RFID) in the Oil and Gas Industry. Norwegian Oil and Gas Association, Sandnes, Norway.

Vitić-Ćetković, A.; Bauk, S. 2014. E-services and positioning of passenger ports in the context of cruise tourism promotion, Promet - Traffic\&Transportation 26(1): 83-93. http://doi.org/10.7307/ptt.v26i1.1282 